\title{
Comparative airway response to high- versus low-molecular weight agents in occupational asthma
}

\author{
M-H. Dufour*, C. Lemière ${ }^{\#}$, P. Prince* and L-P. Boulet*
}

ABSTRACT: Airway responses to occupational agents in sensitised workers may vary clinically and physiologically. The patterns of change in airway responsiveness, type of response and fall in expiratory flows following laboratory exposure to high- or low-molecular weight agents (HMW and LMW agents, respectively) were compared in sensitised workers.

Data on workers who underwent specific inhalation challenges with occupational sensitisers (117 exposed to HMW agents and 130 to LMW agents) were collected from their medical charts.

Maximum falls in forced expiratory volume in one second (FEV1) were of similar magnitude for both types of agents. Compared with HMW agents, LMW agents induced more frequently late or dual responses and higher increases in airway responsiveness. After exposure to HMW agents, there was a mean $\pm S D$ reduction in doubling concentrations of methacholine of $0.5 \pm 1.7$ for early responses, compared with $2.8 \pm 1.2$ and $1.4 \pm 2.0$ for late and dual responses, respectively. Isolated early responses were more frequently found in females, smokers, workers with a higher $\%$ predicted $\mathrm{FEV}_{1}$ and higher provocation concentration causing a $20 \%$ fall in $\mathrm{FEV}_{1}$, and in those with longer asthma duration.

Workers' characteristics, as well as the type of agent they are sensitised to, may help to predict the type of response after specific inhalation challenge.

KEYWORDS: Airway inflammation, airway responsiveness, occupational asthma, specific inhalation challenge

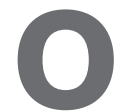
ccupational asthma (OA) is one of the most common occupational ailments. It is defined as a disease characterised by variable airflow limitation and/or airway hyperresponsiveness due to causes and conditions attributable to a particular occupational environment and not to stimuli encountered outside the workplace [1]. The specific-inhalation challenge (SIC) is recognised as a good reference diagnostic test for OA [2]. This test is performed in specialised centres and involves exposing the worker to the suspected harmful agent using incremental doses, in order to detect any fall in expiratory flows and/or any increase in airway responsiveness (AR) [3].

There are $>300$ known OA-causal agents and these are divided into high-molecular weight (HMW) agents, such as flour, latex, laboratory animal proteins and grain dust, and low-molecular weight (LMW) agents, such as isocyanates, plicatic acid, metals and anhydrides [3]. HMW agents are considered to act as common airborne allergens through immunoglobulin (Ig)E-mediated responses, while the mechanisms by which LMW agents induce asthma may be different, possibly involving nonspecific immune mechanisms [4].

Up until now, the few studies available on patterns of response to occupational agents have demonstrated variable patterns of response to HMW and LMW agents in limited numbers of patients [5]. Furthermore, how worker's characteristics may influence the pattern of response to sensitising agents remains to be explored. The various types of responses identified include: 1) early responses (EAR), usually defined as a fall in forced expiratory volume in one second (FEV1) of $20 \%$ or more in the first hour following the end of exposure; 2) late responses (LARs), characterised by a decrease of $\geqslant 15-20 \%$ between 2 and $8 \mathrm{~h}$ after exposure; 3 ) dual responses (DARs), a combination of both types of reactions with a recovery of FEV1 between the two reactions, without the use of a bronchodilator; and 4) atypical responses (AARs), where such recovery is not observed $[1,3]$.

HMW agents seem to mostly induce EARs or DARs while LMW agents produce EARs, LARs,

\section{AFFILIATIONS}

*Unité de recherche en pneumologie, Centre de recherche de l'Hôpital Laval, Institut Universitaire de cardiologie et de pneumologie, Hôpital Laval, Quebec, and

${ }^{\#}$ Service de pneumologie, Hôpital du Sacré-Cœur, Université de Montréal Montreal, QC, Canada.

\section{CORRESPONDENCE}

L-P. Boulet

Hôpital Laval

2725 Chemin Sainte-Foy

Quebec

Canada G1V 4G5

Fax: 14186564762

E-mail: Ipboulet@med.ulaval.ca

Received:

September 112007

Accepted after revision:

December 082008

SUPPORT STATEMENT

C. Lemière holds a new investigator scholarship from the Canadian Institutes of Health Research (Ottawa Canada)

STATEMENT OF INTEREST A statement of interest for L-P. Boulet can be found at

www.erj.ersjournals.com/misc/ statements.dtl

Online ISSN 1399-3003 
DARs or AARs [3]. MALO et al. [5] previously looked at clinical and functional parameters among three groups of subjects with OA caused by Western red cedar, isocyanates and HMW agents. In the present study, having a nonimmediate reaction at the time of SIC, being continuously exposed to the agent and being younger slightly increased the risk of developing symptoms in subjects with OA.

Herein, the authors present the results of an analysis of the comparative influence of HMW and LMW agents on patterns of response, expiratory flows and $\mathrm{AR}$ in a large group of patients with OA proven through SIC. To the best of the current authors' knowledge, this is the first study of this magnitude with such a diversity of sensitising agents.

\section{METHODS}

\section{Subjects and study design}

A retrospective review was conducted of all the medical charts of subjects aged $\geqslant 18$ yrs with OA confirmed by a positive SIC between 2001 and 2005 in two Canadian referral centres for OA (Hôpital Laval, Quebec City, and Hôpital du Sacré-Cœur, Montreal). Workers had experienced no upper or lower respiratory tract infection within the 4 weeks prior to the challenges and they all had a stable respiratory condition. Medical charts were reviewed by trained research assistants. Results of the respiratory function tests, methacholine and SICs, in addition to data on medical history, were analysed.

\section{Definitions}

The present authors defined an EAR as a per cent fall in FEV1 of $\geqslant 20 \%$ within $1 \mathrm{~h}$ from the last inhalation of the sensitising agent during a SIC. A LAR was defined as a fall in FEV1 of $\geqslant 15 \%$ between $2-8 \mathrm{~h}$ following challenge. A DAR was defined as the combination of an EAR and a LAR. Finally, an AAR was defined as an early fall in FEV1, progressing to a maximum reaction 5-6 h later or a "square waved" response, similar to a DAR but with only partial recovery $(<10 \%)$ between the immediate and late falls in FEV1 or in the form of a prolonged immediate reaction.

\section{Spirometry and methacholine challenge}

Spirometry was performed according to the recommendations of the American Thoracic Society [6]. Methacholine challenge tests were performed according to the method reported by JUNIPER et al. [7]. Responses were expressed as the provocation concentration causing a 20\% fall in FEV1 (PC20), obtained from the log-dose response curve. The change in AR was expressed in the number of doubling concentrations of methacholine.

\section{Skin prick tests}

Skin prick tests were performed with commercial extracts (Omega; Montreal, QC, Canada) from common inhalants (trees, grasses, ragweed, house-dust mites, hormodendrum, aspergillus, alternaria, cat and dog). A positive response was defined as a weal diameter of $\geqslant 3 \mathrm{~mm}$ at $10 \mathrm{~min}$, in the absence of reaction to a control diluent, and with a positive response to histamine phosphate $\left(10 \mathrm{mg} \cdot \mathrm{mL}^{-1}\right)$ as previously described [8]. A subject was considered to be atopic if at least one positive response was observed.

\section{SIC}

SICs were performed according to previously published methods $[9,10]$. For each series of challenges, a control day was performed with the subjects being initially exposed to a nonsensitising agent (e.g. lactose or solvents). During SIC, FEV1 was measured at baseline and every $10 \mathrm{~min}$ for the first hour, every $30 \mathrm{~min}$ for the second hour, and then hourly for $\geqslant 8 \mathrm{~h}$ after the end of exposure [10]. On the following days, the time or dose of exposure to the occupational agent was progressively increased. For agents causing OA through an IgEmediated mechanism, such as HMW substances, increasing dose exposure was performed progressively over 1 day, while the exposure for agents causing OA without a recognised IgEmediated mechanism was completed over several days. Occasionally, concurrent treatment with inhaled corticosteroids (ICS) could be maintained during the investigation if considered necessary, but long-acting $\beta_{2}$-agonists were stopped $72 \mathrm{~h}$ before the tests, when possible. Short-acting inhaled $\beta_{2}$-agonists were withheld $\geqslant 6 \mathrm{~h}$ before the challenges.

\section{Statistical analysis}

No statistical analyses were completed with subjects who had an atypical reaction as the number of subjects with such a response was too low. Between-factors interaction was considered in the statistical model. Some variables were logtransformed to stabilise variance. The univariate normality assumptions were verified with the Shapiro-Wilk tests, and the Brown and Forsythe's variation of Levene's test statistics was used to verify the homogeneity of variances. In order to determine the factors associated with the reaction type (EAR versus other), a stepwise logistic regression analysis was performed. Data were expressed using mean \pm SD. According to the data distribution in the comparison of LMW versus HMW sensitised subjects, an unpaired t-test or Chi-squared test was used. Data were analysed using a two-way ANOVA model. One factor (way) was associated to the comparison among the three groups of subjects (EAR, LAR and DAR) while the other factor was associated to the comparison between results from LMW allergens and HMW allergens. The results were considered significant at a $p$-value $\leqslant 0.05$.

\section{RESULTS}

\section{Subject characteristics}

Out of the 247 medical charts reviewed, 117 subjects were sensitised to HMW agents and 130 to LMW agents. Subjects' characteristics are summarised in table 1 . These characteristics were similar in both groups except for sex and smoking habit. Indeed, a higher proportion of males were sensitised to LMW $(76 \%)$ compared with HMW agents $(53 \%$; $\mathrm{p}<0.0001)$, while this proportion was similar in females. There were more nonsmokers and ex-smokers among subjects sensitised to LMW and more smokers in those sensitised to HMW $(p<0.0001)$. The prevalence of atopy and the latency period between the onset of exposure and the onset of asthma symptoms were similar in both groups. Subjects were away from work for variable timeperiods, ranging from days to years.

There were no significant differences in the proportion of workers sensitised to LMW using ICS $(n=89,68 \%)$ compared with those with HMW-related OA $(n=72,62 \% ; p>0.05)$. Whether workers were taking ICS or not had no influence on 


\begin{tabular}{|c|c|c|}
\hline & LMW agents & HMW agents \\
\hline Subjects & $130(53)$ & $117(47)$ \\
\hline Age yrs & $41.0 \pm 11.4$ & $40.5 \pm 11.0$ \\
\hline \multicolumn{3}{|l|}{ Sex } \\
\hline Male & $99(76)^{f}$ & $62(53)$ \\
\hline Female & $31(24)$ & $55(47)$ \\
\hline Atopy & $78(60)$ & $86(74)$ \\
\hline \multicolumn{3}{|l|}{ Smoking habit pack-yrs } \\
\hline Nonsmokers ${ }^{\#}$ & $0 \pm 0^{f}$ & $0 \pm 0$ \\
\hline Smokers & $17.5 \pm 9.0^{f}$ & $16.9 \pm 10.5$ \\
\hline Ex-smokers $^{+}$ & $12.2 \pm 13.0^{f}$ & $13.3 \pm 9.5$ \\
\hline Duration of asthma yrs & $6.0 \pm 8.0$ & $6.9 \pm 8.3$ \\
\hline Duration of exposure yrs & $11.5 \pm 10.9$ & $13.7 \pm 11.0$ \\
\hline Latency period ${ }^{\S}$ yrs & $7.3 \pm 8.9$ & $7.3 \pm 7.9$ \\
\hline \multicolumn{3}{|l|}{ Baseline FEV 1} \\
\hline L & $3.0 \pm 0.8$ & $2.9 \pm 0.9$ \\
\hline$\%$ pred & $88.2 \pm 18.2$ & $88.7 \pm 18.5$ \\
\hline \multicolumn{3}{|l|}{ Baseline FVC } \\
\hline L & $4.2 \pm 1.0$ & $4.0 \pm 1.0$ \\
\hline$\%$ pred & $98.3 \pm 15.9$ & $102.5 \pm 40.1$ \\
\hline $\begin{array}{l}\text { Baseline } \mathrm{PC}_{20} \text { methacholine } \\
\mathrm{mg} \cdot \mathrm{mL}^{-1}\end{array}$ & $3.5(0.02-128)$ & $2.7(0.04-128)$ \\
\hline
\end{tabular}

Data are presented as $n(\%)$, mean \pm SD or geometric mean (range). LMW: lowmolecular weight; HMW: high-molecular weight; FEV1: forced expiratory volume in one second; \% pred: \% predicted; FVC: forced vital capacity; PC20: provocation dose causing a $20 \%$ fall in FEV1. ${ }^{*}: \mathrm{n}=49$ and 31 for LMW and HMW, respectively; " $n=17$ and 46 for $L M W$ and HMW, respectively; ${ }^{+}: n=62$ and 39 for LMW and HMW, respectively; ${ }^{\S}$ : onset of exposure, onset of asthma symptoms; ${ }^{f}: \mathrm{p}<0.0001$.

the maximum fall in FEV1 during SIC or on the change in the PC20, before versus after the challenge $(p=0.4)$. The use of ICS was not associated with a specific type of asthmatic reaction $(\mathrm{p}=0.1$, data not shown).

\section{Sensitising agents}

The various sensitising agents responsible for OA are shown in table 2. In the group sensitised to HMW agents, flour and seafood were the more prevalent (13.8 and $12.6 \%$ of workers, respectively). For LMW agents, isocyanates, wood dust and metals were the most prevalent $(17.8,6.9$ and $6.9 \%$, respectively).

\section{Magnitude of the fall in FEV 1 after SIC}

On control days, no significant respiratory symptoms or change in FEV1 were noted. There were no significant differences between the mean maximum fall in FEV1 during SIC between reactions to LMW and HMW agents $(28.6 \pm 13.8$ and $28.1 \pm 12.2$, respectively; $\mathrm{p}>0.05$ ). In both groups, DARs were associated with a greater maximum fall in FEV1 than EARs (LMW: $38.0 \pm 9.1 \%$ versus $30.3 \pm 12.4 \%$, respectively; HMW: $34.9 \pm 10.3 \%$ versus $28.7 \pm 11.2 \%$, respectively; $p=0.002$, fig. 1). The number of more severe reactions (fall in FEV1 $>40 \%)$ was similar in both groups (19 (14.6\%) occasions and 16 (13.7\%) occasions in LMW and HMW, respectively).

\section{Patterns of response following SIC}

Following SIC, patterns of response were different for HMW and LMW agents. Workers presenting with an EAR, a LAR, a DAR and an AAR were 61, 9, 14 and $0 \%$, respectively, following HMW agent challenges and 32, 23, 17 and 3\%, respectively, with LMW agents $(\mathrm{p}<0.001$, ANOVA; table 2$)$. Subjects exposed to HMW agents presented with EARs more frequently $(61 \%)$ than subjects exposed to LMW agents $(32 \%)$, whereas subjects exposed to LMW agents presented more frequently with LARs (23\%) and AARs (3\%) than those exposed to HMW agents ( 9 and $0 \%$, respectively; $\mathrm{p}<0.05$ ).

Immediate reactions were common in smokers (odds ratio (OR) $2.42,95 \%$ confidence interval (CI) 1.06-5.52) and ex-smokers (OR 2.09, 95\% CI 1.04-4.21; p=0.04), while nonsmokers presented more often with nonimmediate reactions $(p=0.005)$. Patients with an immediate reaction following SIC had a longer asthma duration (mean \pm SD: $7.4 \pm 0.8$ ) than those having a nonimmediate reaction $(5.3 \pm 0.6, p=0.027)$. The baseline percent of predicted FEV1 was higher for those with an immediate reaction $(91.3 \pm 1.3)$ than for nonimmediate reactions $(86.7 \pm 1.4$; $\mathrm{p}=0.02)$. The same pattern was observed for the baseline percentage of predicted forced vital capacity $(104.0 \pm 3.2$ versus $96.8 \pm 1.3, \mathrm{p}=0.04)$.

Furthermore, subjects with a higher baseline PC20 had at greater risk of experiencing immediate reactions (OR 1.02, 95\% CI 1.00-1.04). There were no other significant differences in the prevalence of the various types of responses in both groups in relation to the duration of exposure to the offending agents, the latency period, age, duration of asthma and atopy.

\section{Airway responsiveness}

Prior to SIC, PC20 was higher in workers experiencing immediate reactions (geometric mean (range) $3.36(0.02-128)$ ) than for nonimmediate reactions $(2.3(0.04-64), \mathrm{p}=0.03)$. The post-challenge increase in $\mathrm{AR}$, in the number of double concentrations of methacholine, was higher following exposure to LMW $(1.8 \pm 2.3)$ compared with HMW agents $(0.8 \pm 1.8$, $\mathrm{p}=0.0006)$. Furthermore, if this parameter is compared with the type of reaction observed during SIC, the fall in doubling concentrations of methacholine after immediate responses following exposure to HMW $(0.5 \pm 1.7)$ was lower than for LARs $(2.7 \pm 1.2)$ and DARs $(1.4 \pm 2.0, p=0.0005$; fig. 2$)$. For the nonimmediate reactions, there was a weak negative correlation $(\mathrm{r}=-0.32, \mathrm{p}=0.018)$ between the difference in PC20 before and after SIC and the maximum FEV1 fall during the challenge. No correlation was found between these parameters for immediate reactions $(\mathrm{p}>0.05)$.

\section{DISCUSSION}

The present study shows that exposure to LMW agents induces LARs more frequently than HMW agents, while EARs are more common after exposure to the latter. Increases in AR are of smaller magnitude with HMW-induced EARs than LARs. Males were more frequently exposed to LMW than to HMW whereas females were equally exposed to LMW and HMW. This is likely to be explained by the fact that LMW are often found in jobs where males are represented in a larger proportion than females. Compared with nonimmediate responses, immediate responses were found more frequently 
TABLE 2 Types of occupational agents and types of responses following specific inhalation challenges

\begin{tabular}{|c|c|c|c|c|c|c|}
\hline & Workers & Early reaction & Late reaction & Dual reaction & Atypical reaction & Unspecified in chart \\
\hline \multicolumn{7}{|l|}{ LMW agents } \\
\hline $\mathrm{HDI}$ & $22(8.9)$ & 9 & 6 & 5 & 1 & 1 \\
\hline MDI & $9(3.6)$ & 5 & 3 & 1 & 0 & 1 \\
\hline TDI & $5(2.0)$ & 2 & 2 & 0 & 0 & 1 \\
\hline Plicatic acid (white or red cedar) & $16(6.5)$ & 7 & 3 & 5 & 0 & 1 \\
\hline Wood dust & $17(6.9)$ & 1 & 8 & 3 & 1 & 4 \\
\hline Hairdresser products & $7(2.8)$ & 2 & 3 & 2 & 0 & 0 \\
\hline Epoxy & $4(1.6)$ & 2 & 0 & 2 & 0 & 0 \\
\hline Gums & $3(1.2)$ & 1 & 0 & 0 & 0 & 2 \\
\hline Dyes and fabrics & $4(1.6)$ & 1 & 0 & 2 & 0 & 1 \\
\hline Total & $130(52.6)$ & 41 & 30 & 22 & 4 & 33 \\
\hline \multicolumn{7}{|l|}{ HMW agents } \\
\hline Flour & $34(13.8)$ & 27 & 0 & 2 & 0 & 5 \\
\hline Plants and grain dust & $16(6.5)$ & 10 & 0 & 5 & 0 & 1 \\
\hline Seafood/fish & $31(12.6)$ & 21 & 3 & 7 & 0 & 0 \\
\hline Latex & $7(2.8)$ & 4 & 0 & 0 & 0 & 3 \\
\hline Animal-derived allergens & $20(8.1)$ & 7 & 7 & 3 & 0 & 3 \\
\hline Leather & $2(0.8)$ & 0 & 0 & 0 & 0 & 2 \\
\hline Enzymes & $2(0.8)$ & 2 & 0 & 0 & 0 & 0 \\
\hline Talc & $1(0.4)$ & 0 & 0 & 0 & 0 & 1 \\
\hline Unknown & $4(1.6)$ & 0 & 1 & 0 & 0 & 3 \\
\hline Total & $117(47.4)$ & 71 & 11 & 17 & 0 & 18 \\
\hline
\end{tabular}

Data are presented as n (\%) or n. LMW: low-molecular weight; HDI: hexamethylene diisocyanate; MDI: methylene diphenyl diisocyanate; TDI: toluene diisocyanae; HMW high-molecular weight.
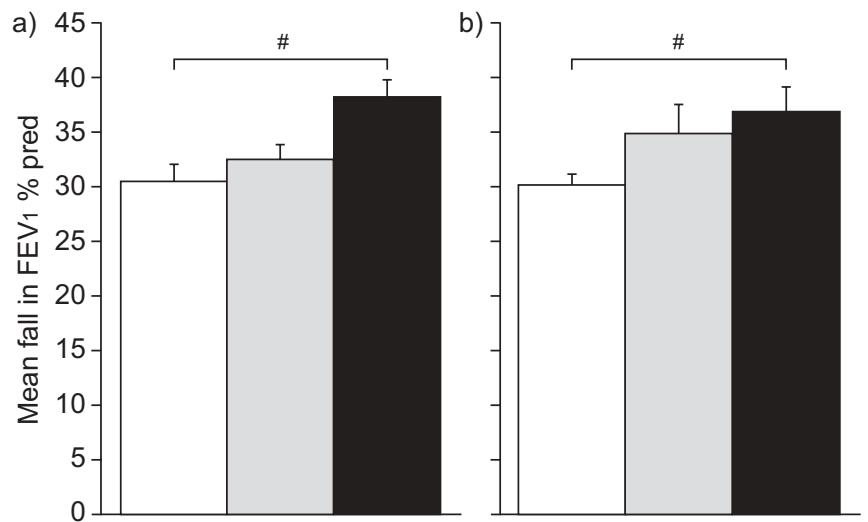

FIGURE 1. Magnitude of the asthmatic response during specific inhalation challenges in a) low-molecular weight agents and b) high-molecular weight agents. $\square$ : early reaction; $\square$ : late reaction; $\mathbf{\square}$ : dual reaction. FEV1: forced expiratory volume in one second; \% pred: \% predicted. ${ }^{*}: p=0.002$. in females, smokers, workers with a higher predicted FEV1 and PC20, and in those with a longer duration of asthma.

Definitions of EARs and LARs vary between studies, ranging from 15 to $20 \%$ fall in FEV1 [5, 11]. The present authors used a $20 \%$ fall in FEV1 for an EAR and a $15 \%$ fall for a LAR. The majority of the current study subjects experienced falls in FEV1 $>20 \%$ both for EARs and LARs, with very few subjects, between 15 and $20 \%$, making the data comparable to other studies using a $20 \%$ fall to define a LAR.

MALO et al. [5] previously studied the responses to three types of LMW agents and various HMW substances, with the aim of determining how these exposures influenced the development of symptoms in OA. Western red cedar, isocyanates and HMW agents induced a nonimmediate response in 45,38 and $14 \%$ of workers, respectively, while they induced an immediate reaction and a DAR in 55,62 and $86 \%$ of the cases, respectively. ZAMMIT-TABONA et al. [12] showed that out of six subjects showing a specific asthmatic reaction to methylene diphenyl 


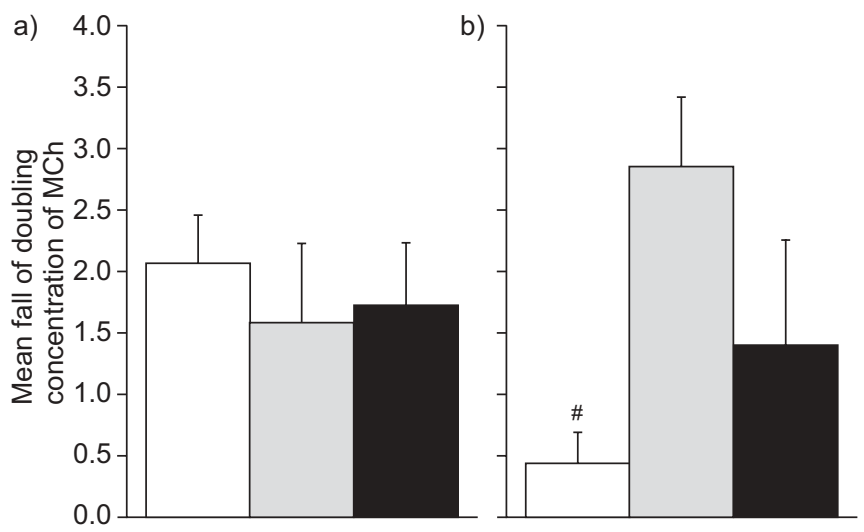

FIGURE 2. Mean fall in double concentrations of methacholine (MCh) according to the type of response in a) low-molecular weight agents and b) high-molecular weight agents. $\square$ : early reaction; $\mathbf{1}$ : late reaction; $\mathbf{a}$ : dual reaction. ${ }^{*}$ : $p=0.0005$.

diisocyanate challenge, four had a LAR and two had a DAR. The present study extends these observations on a wider range of sensitising agents. A LAR was found to be more often associated to LMW agents and an EAR to HMW agents, in keeping with the previous report. This is probably related to the fact that HMW agents usually induce OA through an IgEmediated mechanism [4], while for LMW agents, the mechanisms involved are still to be clarified [9, 13-15]. In this respect, HMW agents act mostly as common nonoccupational allergens, IgE-dependent mechanisms inducing an EAR or a DAR, as in the classical type of allergen-induced asthma [3]. PERRIN et al. [16] reported that LMW agents are more often associated with an AAR. In the present study, although the number of AARs was smaller than the numbers reported by PERRIN et al. [16], all four subjects who had an AAR were sensitised to LMW agents. The study by PERRIN et al. [16] focused on the characterisation of the patterns of asthmatic reactions. All the patterns of reactions were thoroughly analysed by the physicians in charge of the study. The present study was a retrospective study that relied on the information included in the medical charts of the subjects. Therefore, some AAR may have been confused with or interpreted as typical reactions in the current study. These findings emphasise the need of performing a progressive exposure to LMW spread over a few days during the SIC in order to minimise potentially severe isolated, late asthmatic reactions.

According to previous observations [5], sensitisation to red cedar or isocyanates may occur after a shorter time interval than for HMW agents. However, no difference in the latency period between the onset of symptoms and the duration of exposure was found between HMW and LMW agents. In the current study, the LMW group was composed of a large variety of agents, in contrast to previous studies that included only red cedar and isocyanates [5, 17]. The length of time necessary to become sensitised may depend upon, among other factors such as genetics [18] or the concentration of inhaled agents [9], the nature of each agent rather than on only the molecular weight of the agent.

Following SIC, a smaller increase was observed in AR following an EAR induced by HMW agents compared with a LAR and DAR. This difference in changes in airway responsiveness is possibly due to the mode of exposure to the offending agent, although the magnitude of the asthmatic response, in keeping with the method used, aiming at a $20 \%$ fall in FEV1, was similar in both groups. It could be due to the fact that AR was measured at the end of the last SIC in the case of EARs, whereas the methacholine challenge was performed the following day in subjects with a LAR since a bronchodilator had to be administered at the end of the day to reverse the asthmatic reaction. However, in allergic asthma, it has been shown that LARs are associated with a more intense airway inflammatory response than EARs; such responses are being considered responsible for the increase in AR following exposure to the offending agent $[19,20]$. The intensity and type of inflammatory response induced by the various agents may explain the differences observed in this parameter.

The higher prevalence of isolated immediate responses in females may be due to the higher prevalence of sensitisation (and exposure) to HMW agents compared with males. The reason why smokers show a higher frequency of isolated immediate responses than nonsmokers is unclear. It is thought there may be an influence of smoke-related substances on the pattern of inflammation, and previous observations have shown some inhibitory effects of allergic and immune mechanisms, e.g. either in asthma or in allergic alveolitis [21, 22]. However, increased immediate responses observed in subjects with higher predicted FEV1 and PC20 may indicate an influence of airway calibre and responsiveness on the pattern of airway response to occupational agents. It may be suggested that subjects with increased airflow limitation or AR have more bronchial inflammation and possibly remodelling than the others, and that this may influence responses to occupational agents. With respect to increased immediate responses with a longer duration of asthma, it has been previously shown that the latency period before the beginning of symptoms and withdrawal from work was longer in workers exposed to HMW substances, which induce more frequent immediate responses [9].

In conclusion, the present authors have shown that there are significant differences in the type of airway changes induced by low- and high-molecular weight agents. These results could help to better understand the physiopathology of occupational asthma and predict the outcome of these workers. However, how occupational agents might cause occupational asthma, particularly for low-molecular weight agents, remains to be studied. The analysis of the type of airway response induced by these agents and the outcome of workers following withdrawal will help in understanding the mechanisms involved. Further studies should focus on comparing the clinical/physiological responses in occupational asthma versus work-aggravated asthma, as well as their relationships with bronchial inflammatory responses. In this respect, the noninvasive methods of assessment of airway inflammation developed over the last years may help find answers about these processes.

\section{ACKNOWLEDGEMENTS}

The authors would like to thank S. Simard (Hôpital Laval, Quebec, QC, Canada) for the statistical analyses. 


\section{REFERENCES}

1 Bernstein IL, Chan-Yeung M, Malo J-L, Bernstein DI. eds. Asthma in the Workplace. 2nd Edn. New York, Informa Healthcare, 1999.

2 Tarlo SM, Boulet LP, Cartier A, et al. Canadian Thoracic Society guidelines for occupational asthma. Can Respir J 1998; 5: 289-300.

3 Chan-Yeung M, Malo JL. Occupational asthma. N Engl J Med 1995; 333: 107-112.

4 Chan-Yeung M, Malo JL, Tarlo SM, et al. Proceedings of the first Jack Pepys Occupational Asthma Symposium. Am J Respir Crit Care Med 2003; 167: 450-471.

5 Malo JL, Ghezzo H, D'Aquino C, L'Archeveque J, Cartier A, Chan-Yeung M. Natural history of occupational asthma: relevance of type of agent and other factors in the rate of development of symptoms in affected subjects. $J$ Allergy Clin Immunol 1992; 90: 937-944.

6 Standardization of Spirometry, 1994 Update. American Thoracic Society. Am J Respir Crit Care Med 1995; 152: 1107-1136.

7 Juniper EF, Cockcroft DW, Hargreave FE. : Histamine and methacholine inhalation test: a laboratory tidal breathing protocol. 2nd Edn. Lund, Astra Draco AB, 1994.

8 Pepys J. "Atopy": a study in definition. Allergy 1994; 49: 397-399.

9 Vandenplas O, Malo JL. Inhalation challenges with agents causing occupational asthma. Eur Respir J 1997; 10: 2612-2629.

10 Cartier A. Definition and diagnosis of occupational asthma. Eur Respir J 1994; 7: 153-160.

11 Sterk PJ, Fabbri LM, Quanjer PH, et al. Airway responsiveness. Standardized challenge testing with pharmacological, physical and sensitizing stimuli in adults. Report Working Party Standardization of Lung Function Tests, European Community for Steel and Coal. Official Statement of the European Respiratory Society. Eur Respir J 1993; 6: Suppl. 16, 53-83.

12 Zammit-Tabona M, Sherkin M, Kijek K, Chan H, ChanYeung M. Asthma caused by diphenylmethane diisocyanate in foundry workers. Clinical, bronchial provocation, and immunologic studies. Am Rev Respir Dis 1983; 128: 226-230.

13 Mapp CE, Boschetto P, Miotto D, De Rosa E. Asthma induced by isocyanates: a model of IgE-independent asthma. Acta Biomed Ateneo Parmense 2005; 76: Suppl. 2, 15-19.

14 Jones MG, Floyd A, Nouri-Aria KT, et al. Is occupational asthma to diisocyanates a non-IgE-mediated disease? J Allergy Clin Immunol 2006; 117: 663-669.

15 Wisnewski $\mathrm{AV}$, Stowe $\mathrm{MH}$, Cartier $\mathrm{A}$, et al. Isocyanate vapor-induced antigenicity of human albumin. J Allergy Clin Immunol 2004; 113: 1178-1184.

16 Perrin B, Cartier A, Ghezzo H, et al. Reassessment of the temporal patterns of bronchial obstruction after exposure to occupational sensitizing agents. J Allergy Clin Immunol 1991; 87: 630-639.

17 Malo JL, Ghezzo H, L'Archeveque J, Cartier A. Late asthmatic reactions to occupational sensitizing agents: frequency of changes in nonspecific bronchial responsiveness and of response to inhaled $\beta_{2}$-adrenergic agent. $J$ Allergy Clin Immunol 1990; 85: 834-842.

18 Bignon JS, Aron Y, Ju LY, et al. HLA class II alleles in isocyanate-induced asthma. Am J Respir Crit Care Med 1994; 149: 71-75.

19 Boulet LP, Cartier A, Thomson NC, Roberts RS, Dolovich J, Hargreave FE. Asthma and increases in nonallergic bronchial responsiveness from seasonal pollen exposure. J Allergy Clin Immunol 1983; 71: 399-406.

20 Gauvreau GM, Watson RM, O'Byrne PM. Kinetics of allergen-induced airway eosinophilic cytokine production and airway inflammation. Am J Respir Crit Care Med 1999; 160: 640-647.

21 Blanchet MR, Israel-Assayag E, Cormier Y. Inhibitory effect of nicotine on experimental hypersensitivity pneumonitis in vivo and in vitro. Am J Respir Crit Care Med 2004; 169: 903-909.

22 Patel AM, Ryu JH, Reed CE. Hypersensitivity pneumonitis: current concepts and future questions. J Allergy Clin Immunol 2001; 108: 661-670. 